\title{
Improvement of in vitro fertilisation after treatment with buserelin, an agonist of luteinising hormone releasing hormone
}

\author{
A J RUTHERFORD, R J SUBAK-SHARPE, K J DAWSON, R A MARGARA, S FRANKS, \\ R M L WINSTON
}

\begin{abstract}
Treatment with buserelin, an agonist of luteinising hormone releasing hormone, and human menopausal gonadotrophin was compared with the conventional treatment of clomiphene citrate and human menopausal gonadotrophin in the outcome of in vitro fertilisation. Seventy seven infertile women had 83 cycles of treatment with buserelin and human menopausal gonadotrophin, and concurrently another 328 infertile women were treated with clomiphene citrate and human menopausal gonadotrophin. Seven $(8 \%)$ cycles were cancelled owing to inadequate superovulation or ovarian hyperstimulation in the women receiving buserelin and $103(31 \%)$ were cancelled because of poor follicular development in those receiving clomiphene citrate. The mean number of oocytes recovered was significantly higher with buserelin (9.5 (SD 4.5) $v 5.5(2.2))$ as was the mean number of embryos obtained $(4.3(2.4) v 2.9(1.7))$. Significantly more women who had an embryo transfer became clinically pregnant after treatment with buserelin $(53 \%(30 / 57) v 30 \%(48 / 159)$, or $36 \%$ $v 14 \%$ of treatment cycles). Altogether $33 \%(10)$ of pregnancies in women treated with buserelin were multiple compared with $23 \%$ (11) in those treated conventionally. Of the 17 completed pregnancies in women treated with buserelin, 11 resulted in the birth of live babies (eight singletons, two sets of twins, and one set of triplets) and six failed, five before 12 weeks' gestation and one at 22 weeks. The 13 continuing pregnancies ( 32 weeks) were eight singletons, two sets of twins, and three sets of triplets. Of the $\mathbf{4 8}$ completed pregnancies in women treated with clomiphene citrate, 35 resulted in the birth of live babies ( 26 singletons, five
\end{abstract}

Institute of Obstetrics and Gynaecology, Royal Postgraduate Medical School, Hammersmith Hospital, London W12 0HS

A J RUTHERF()RD, MRCOG, research senior registrar

R J SUBAK-SHARPE, MRCOG, research senior registrar

K J DAWSON, MSC, embryologist

R A MARGARA, MD, consultant and senior lecturer in fertility studies

R M L WINST()N, FRCO(i, professor of fertility studies

Department of Obstetrics and Gynaecology, St Mary's Hospital, London W2 $S$ FRANKS, MI), MRCP, senior lecturer and consultant endocrinologist

Correspondence to: Professor Winston. sets of twins and four sets of triplets) and 13 failed, eleven before 12 weeks' gestation and two by 27 weeks.

Buserelin increased the chance of pregnancy after in vitro fertilisation compared with conventional treatment, but the risk of multiple pregnancy may be increased.

\section{Introduction}

Nearly 10 years after the first baby was born as a result of in vitro fertilisation, this treatment is still largely unsuccessful. The latest figures available show that only $11 \%$ of women had a pregnancy and $9 \%$ a live baby after a single cycle of treatment in the United Kingdom.' Effective superovulation is essential for in vitro fertilisation as rates of pregnancy are related to the numbers of good quality oocytes recovered and fertilised and of embryos transferred to the uterus.' Agonists of luteinising hormone releasing hormone abolish the spontaneous release of gonadotrophin by the pituitary gland and protect oocytes from inappropriate exposure to luteinising hormone, which is thought to be detrimental to normal maturation of the egg. ${ }^{3+}$ Moreover, the luteinising hormone releasing hormone agonist buserelin reduces follicle stimulating hormone concentration producing temporary hypogonadotrophic hypogonadism. This allows follicles to be stimulated by exogenous follicle stimulating hormone earlier in the follicular recruitment process (D R Meldrum et al, fourth world conference on in vitro fertilisation, Melbourne, 1985), which may account for the increased yield of oocytes with this treatment."

We report the results obtained with buserelin and human menopausal gonadotrophin compared with those obtained with the conventional treatment of clomiphene citrate and human menopausal gonadotrophin in the outcome of in vitro fertilisation.

Patients and methods

PATIENTS

Seventy seven infertile women were given buserelin followed by induction of ovulation by human menopausal gonadotrophin in 83 cycles of treatment for in vitro fertilisation, and during the same time 328 women received clomiphene citrate and human menopausal gonadotrophin. 
Table I shows the causes of infertility in both groups of women. Although the study was not randomised, 52 of the 77 patients receiving buserelin had had cycles of treatment for in vitro fertilisation that had failed or they had well defined evidence of the polycystic ovary syndrome, ${ }^{7}$ or both, and would therefore be expected to respond poorly to in vitro fertilisation; indeed, 18 of the 22 patients with the polycystic ovary syndrome had between them a total of 40 previous failed cycles of treatment, with most $(27 / 40(68 \%))$ being cancelled before collection of the egg, primarily because of an inappropriate surge of luteinising hormone (22/27). The remaining 25 patients had tubal damage as the sole cause of infertility and were randomly allocated to treatment with buserelin. The mean age of those receiving buserelin was 33.3 years and the mean age of those receiving clomiphene citrate 33.5 years.

TABLE I-Causes of infertility in women receiving clomiphene citrate and human menopausal gonadotrophin and in those receiving buserelin and human menopausal gonadotrophin. Values are numbers (percentages) of women

\begin{tabular}{lcc}
\hline \multicolumn{1}{c}{ Cause of infertility } & $\begin{array}{c}\text { Clomiphene citrate and } \\
\text { human menopausal } \\
\text { gonadotrophin } \\
(\mathrm{n}=328)\end{array}$ & $\begin{array}{c}\text { Buserelin and human } \\
\text { menopausal } \\
\text { gonadotrophin } \\
(\mathrm{n}=77)\end{array}$ \\
\hline $\begin{array}{l}\text { Tubal disease alone } \\
\text { Polycystic ovary syndrome with or without } \\
\text { tubal disease }\end{array}$ & $224(68)$ & $37(48)$ \\
$\begin{array}{l}\text { Male factor with or without tubal disease } \\
\text { Endometriosis with or without tubal disease }\end{array}$ & $28(4)$ & $22(29)$ \\
$\begin{array}{l}\text { Unexplained infertility } \\
\text { More than two factors }\end{array}$ & $21(10)$ & $6(8)$ \\
& $11(3)$ & $5(7)$ \\
& $11(3)$ & $3(4)$ \\
\hline
\end{tabular}

\section{METHODS}

Women assigned to treatment with buserelin started taking the drug on day 2 of the menstrual cycle after detailed pelvic ultrasound scanning and measurement of serum oestradiol and luteinising hormone concentrations. Buserelin $300 \mathrm{mg}$ was given intranasally every four hours during waking hours $(1500 \mu \mathrm{g} / \mathrm{day})$. This was continued for 14 days before repeating pelvic ultrasonography and determination of serum hormone values. If the serum oestradiol concentration was below $100 \mathrm{pmol} / 1$ and luteinising hormone concentration below $3 \mathrm{IU} / \mathrm{l}$, and the pelvic ultrasound examination showed a thin endometrial line $(<4 \mathrm{~mm})$ intramuscular human menopausal gonadotrophin was started the following day. If there was inadequate pituitary or gonadal suppression, or both, buserelin was continued for four more days and scans and hormone values re-evaluated. This process was repeated until adequate suppression was observed.

Two ampoules of human menopausal gonadotrophin (150 iu) were given daily up to and including the day of giving human chorionic gonadotrophin. The dose of human menopausal gonadotrophin was increased to three ampoules after six days if the serum oestradiol concentration and pelvic scan indicated no follicular growth. Human chorionic gonadotrophin (10000 iu) was given by intramuscular injection when the three largest follicles were equal to or greater than $17 \mathrm{~mm}$ in diameter and oestradiol values were consistent with the number of developing follicles seen on the ultrasound scan. ${ }^{8}$ Buserelin was discontinued just before human chorionic gonadotrophin was given, which was timed to allow collection of eggs mid-morning, 34 hours later. Transfer of embryo was performed 40 to 48 hours after retrieval of oocytes. The luteal phase was supported with intramuscular injections of progesterone (Gestone $25 \mathrm{mg}$ every eight hours) for 72 hours; subsequently, vaginal progesterone (Cyclogest $200 \mathrm{mg}$ ) was given nightly for 10 nights. Serum concentrations of $\beta$ human chorionic gonadotrophin were measured 14 days after collection of the eggs and any pregnancies confirmed by ultrasonography 14 and 28 days later.

Patients treated conventionally were given clomiphene citrate $50 \mathrm{mg}$ orally for five days starting 12 days before the expected day of ovulation (based on the criteria outlined by McIntosh et al with consecutive or concurrent human menopausal gonadotrophin (two ampoules daily), depending on the length of the menstrual cycle, according to the regimen reported by Hillier et al. ${ }^{10}$ Human menopausal gonadotrophin was discontinued when the lead follicle was $>16 \mathrm{~mm}$ diameter and human chorionic gonadotrophin given by intramuscular injection according to the criteria of Hillier et al. ${ }^{10}$ The collection of eggs was performed 34 hours after human chorionic gonadotrophin was given or a surge of luteinising hormone was detected.

Statistical analysers were carried out with the $\chi^{2}$ and Student's impaired $t$ tests. The $\chi^{2}$ tests were performed on non-independent sets of data, but as the $p$ values were all much less than 0.01 the observed differences may be considered to be real.

Strictly speaking, we used buserelin outside the terms of its licence in this study. Buserelin has, however, been used for more than three years in this country for superovulation in women with similar fertility problems ${ }^{11}$ and is widely used in Europe. After formal discussion with this hospital's drug committee and informal discussion with its ethics committee, it was decided that the usage we report was merely an extension of the drug's regular use and that formal ethical approval was not necessary as our study was not a randomised trial.

\section{Results}

Table II summarises the results overall. Fewer patients had cycles of treatment abandoned after buserelin $(p<0.0001)$. The same criteria were applied in deciding whether to proceed to retrieval of oocytes in both groups. After clomiphene citrate and human menopausal gonadotrophin 54 cycles were cancelled because of poor follicular development, and 44 because of an inappropriate surge of luteinising hormone; four patients had both poor follicular development and high luteinising hormone concentrations and one patient had ovulated. With buserelin and human menopausa gonadotrophin seven cycles were abandoned before the collection of eggs. Four were cancelled for poor response and in the three others human chorionic gonadotrophin was withheld because of a risk of serious ovarian hyperstimulation. In these three cycles buserelin was continued and the crisis avoided; two of the women had a second cycle of treatment with buserelin and smaller doses of human menopausal gonadotrophin and became pregnant.

The average number of days needed to achieve adequate pituitary-gonadal suppression was $20 \cdot 2$ (SD 6.1), although this varied considerably between women. Once suppressed, the number of days of treatment with human menopausal gonadotrophin and, indeed, the amount of human menopausal gonadotrophin required to achieve a similar degree of follicular development was more with buserelin compared with clomiphene citrate (12 (2.3) v 8.6 $(1 \cdot 3)$ days and $26 \cdot 8(10 \cdot 7) v 12(1 \cdot 3)$ ampoules, respectively).

The proportion of patients who had oocytes collected and reached the stage of embryo transfer was similar in both groups (see table II). More oocytes were recovered in women given buserelin (mean $9 \cdot 5(4 \cdot 5)$ v $5 \cdot 5(2 \cdot 2)$ $\mathrm{p}<0.0001$; when one or more oocyte was recovered $(222$ cycles of treatmen with clomiphene citrate and 75 with buserelin) $t=-9 \cdot 509, \mathrm{p}<0.0001$ ). In addition, more embryos were obtained in women given buserelin (mean $4 \cdot 3$ $(2.4)$ v 2.9 (1.7); when one or more oocyte was fertilised (159 cycles of conventional treatment and 57 with buserelin) $t=-5 \cdot 009, \mathrm{p}<0.0001$ ) These findings agree with those from other studies. ${ }^{56}$ The mean number of embryos transferred was similar in both groups, being 2.45 and 2.9 for treatment with clomiphene citrate and buserelin, respectively $\left(\chi^{2}=1 \cdot 77\right.$, $\mathrm{p}=1 \cdot 8$ ).

Thirty six per cent of treatment cycles with buserelin resulted in a clinical pregnancy compared with $15 \%$ after clomiphene citrate $(p<0.0001)$ (table II). Altogether $53 \%$ (30/57) of women who had an embryo transfer after treatment with buserelin had a clinical pregnancy compared with only $30 \%(48 / 159)$ who had conventional treatment $\left(\chi^{2}=9 \cdot 32, \mathrm{p}=0.0023\right)$ (see table III). Indeed, the rate of implantation, as defined by a gestation sac seen on a pelvic ultrasound scan at 28 days after fertilisation or histological evidence of a pregnancy in the case of ectopic or heterotopic pregnancy, improved substantially with buserelin: 47 out of $166(28 \%)$ embryos transferred in the women receiving buserelin implanted compared with only 64 out of $390(16 \%)$ in those receiving clomiphene citrate $\left(\chi^{2}=10 \cdot 6\right.$ $\mathrm{p}=0.001$ )

As expected, transfer of multiple embryos (table III) was more successful in both groups of women and not uncommonly resulted in multiple pregnancy (table IV). The success of embryo transfer was related to the number of fertilised eggs available and not merely to the number of embryos transferred. When five or more embryos were available after treatment with buserelin 17 out of 20 women $(85 \%)$ had established pregnancies shown by ultrasonography; of the remaining three women, two showed evidence of a

TABLE II-Results overall for cycles of treatment with clomiphene citrate and human menopausal gonadotrophin and buserelin and human menopausal gonadotrophin. Values are numbers (percentages)

\begin{tabular}{lcc}
\hline & $\begin{array}{c}\text { Clomiphene citrate and human } \\
\text { menopausal gonadotrophin } \\
(\mathrm{n}=328)\end{array}$ & $\begin{array}{c}\text { Buserelin and human } \\
\text { menopausal gonadotrophin } \\
(\mathrm{n}=83)\end{array}$ \\
\hline Laparoscopies & $225(69)$ & $76(92)$ \\
Cancelled cycles & $103(31)$ & $7(8)^{\star}$ \\
Embryo transfers & $159(49)$ & $57(69)$ \\
Clinical pregnancies & $48(15)$ & $30(36) \dagger$ \\
\hline
\end{tabular}

${ }^{\star} \chi^{2}=16.68, \mathrm{p}<0.0001 . \quad t \chi^{2}=20.06, \mathrm{p}<0.0001$. 
biochemical pregnancy and one had a technically unsatisfactory attempt at embryo transfer. In 16 women who were treated with buserelin we decided to transfer the maximum number of embryos permitted by the Voluntary Licensing Authority (four) because previous embryo transfers had failed. Embryo transfer in these women resulted in 12 clinical pregnancies with one set of triplets and one of twins. In another 18 women treated with buserelin only three embryos were transferred, although more than three were available. Eleven clinical pregnancies resulted, of which five were multiple (three sets of triplets and two of twins) to women with tubal disease as the sole cause of infertility. The remaining three multiple pregnancies with buserelin (one set of triplets, two of twins; table IV) occurred after transfer of two and three embryos; the two women who had three embryos transferred had tubal disease alone.

Table $\mathrm{V}$ shows the outcome of the 48 clinical pregnancies with conventional treatment and the 30 with buserelin. In two of the six sets of triplets in women treated with clomiphene citrate (table IV) all of the babies died; one woman aborted at 24 weeks' gestation and the other delivered live babies at 27 weeks but they all died after 48 hours.

Of the five pregnancies that failed early in women treated with buserelin, three were spontaneous abortions, one was ectopic, and the last heterotopic in which the intrauterine fetus was not viable. In the other heterotopic pregnancy (table IV) removal of the eccyesis allowed the continuation of the intrauterine gestation and a healthy infant was born at term. One woman aborted triplets at 22 weeks and another delivered triplets uneventfully by caesarean section at 35 weeks; the three other triplet pregnancies are currently continuing.

The congenital abnormalities to date are a club foot and an imperforate anus in two babies whose mothers were treated with clomiphene citrate and a mild degree of hypospadias in a male singleton whose mother was treated with buserelin.

TABLE HI-Data on embryo transfer

\begin{tabular}{|c|c|c|c|c|c|}
\hline \multirow[b]{2}{*}{$\begin{array}{c}\text { No of } \\
\text { embryos } \\
\text { available }\end{array}$} & \multirow[b]{2}{*}{$\begin{array}{c}\text { No of } \\
\text { embryos } \\
\text { transferred }\end{array}$} & \multicolumn{2}{|c|}{$\begin{array}{l}\text { Treatment with } \\
\text { clomiphene citrate }\end{array}$} & \multicolumn{2}{|c|}{ Treatment with buserelin } \\
\hline & & $\begin{array}{c}\text { No of } \\
\text { women } \\
(n=159)\end{array}$ & $\begin{array}{c}\text { No of } \\
\text { pregnancies } \\
(\mathrm{n}=48)\end{array}$ & $\begin{array}{c}\text { No of } \\
\text { women } \\
(n=57)\end{array}$ & $\begin{array}{c}\text { No of } \\
\text { pregnancies } \\
(\mathbf{n}=30)\end{array}$ \\
\hline 5 & $\left\{\begin{array}{l}4 \\
3 \\
2\end{array}\right.$ & $\begin{array}{r}18 \\
2\end{array}$ & $\begin{array}{l}7 \\
1\end{array}$ & $\begin{array}{l}9 \\
9 \\
2\end{array}$ & $\begin{array}{l}8 \\
8 \\
1\end{array}$ \\
\hline 4 & $\left\{\begin{array}{l}4 \\
3\end{array}\right.$ & $\begin{array}{r}18 \\
3\end{array}$ & 8 & $\begin{array}{l}7 \\
9\end{array}$ & $\begin{array}{l}4 \\
3\end{array}$ \\
\hline $\begin{array}{l}3 \\
2 \\
1\end{array}$ & $\begin{array}{l}3 \\
2 \\
1\end{array}$ & $\begin{array}{l}34 \\
45 \\
39\end{array}$ & $\begin{array}{r}15 \\
14 \\
3\end{array}$ & $\begin{array}{l}8 \\
7 \\
6\end{array}$ & $\begin{array}{l}3 \\
3\end{array}$ \\
\hline
\end{tabular}

\begin{tabular}{lcc}
$\begin{array}{l}\text { TABLE IV-Data on clinical pregnancy after embryo transfer. } \\
\text { Values are numbers of pregnancies }\end{array}$ \\
\hline Type of pregnancy & $\begin{array}{c}\text { Treatment with } \\
\text { clomiphene citrate }\end{array}$ & $\begin{array}{c}\text { Treatment with } \\
\text { buserelin }\end{array}$ \\
\hline Triplets & 6 & 5 \\
Twins & 5 & 5 \\
Singleton & 34 & 17 \\
Heterotopic & 1 & 2 \\
Ectopic & 2 & 1 \\
\hline \multicolumn{1}{c}{ Total } & 48 & 30 \\
\hline
\end{tabular}

TABLE V-Outcome of clinical pregnancies. Values are numbers of pregnancies

\begin{tabular}{|c|c|c|c|c|c|}
\hline \multirow[b]{2}{*}{ Treatment } & \multicolumn{3}{|c|}{ Completed pregnancy (weeks) } & \multirow{2}{*}{$\begin{array}{l}\text { Continuing } \\
\text { pregnancy } \\
\text { (32 weeks) }\end{array}$} & \multirow[b]{2}{*}{ Total } \\
\hline & -12 & -28 & -40 & & \\
\hline $\begin{array}{l}\text { Clomiphene citrate } \\
\text { Buserelin }\end{array}$ & $\begin{array}{r}11^{\star} \\
58\end{array}$ & $\begin{array}{l}2 \dagger \\
1 \dagger\end{array}$ & $\begin{array}{l}35 \ddagger \\
11 \|\end{array}$ & 139 & $\begin{array}{l}48 \\
30\end{array}$ \\
\hline
\end{tabular}

^Eight abortions, two ectopics, one heterotopic.

†Triplets.

†Twenty six singletons, five sets of twins, four sets of triplets.

TThree abortions, one ectopic, one heterotopic.

||Seven singletons, one heterotopic singleton, two sets of twins, one set of triplets.

ףEight singletons, two sets of twins, three sets of triplets.

\section{Discussion}

These preliminary results suggest that an analogue of luteinising hormone releasing hormone can give substantial improvement in clinical results in a well run programme of in vitro fertilisation. Other workers in small studies using luteinising hormone releasing hormone agonists before superovulation for in vitro fertilisation have shown that this approach is feasible when conventional superovulation treatment has failed. ${ }^{1213}$ This is the first report clearly showing such a dramatic improvement in clinical results in a large series of heterogeneous patients. Although this was not a randomised study, the success rate substantially exceeds that expected, ${ }^{2}$ particularly as $68 \%$ of these women had previously had unsuccessful in vitro fertilisation and were having a second or subsequent cycle of treatment.

An important advantage of this treatment is that far fewer stimulated cycles have had to be abandoned either for poor ovarian response or inappropriate release of luteinising hormone. Fleming et al elegantly showed the effectiveness of luteinising hormone releasing hormone agonist in preventing endogenous release of luteinising hormone and subsequent premature luteinisation for both induction of ovulation in vivo ${ }^{14}$ and superovulation before in vitro fertilisation. ${ }^{11}$ In women who have high luteinising hormone concentrations well before ovulation the eggs are probably exposed to luteinising hormone too early in the cycle to allow adequate maturation. This can result in failure of eggs to fertilise. ${ }^{34}$

The use of buserelin undoubtedly entails higher costs for drugs. The average cost of drugs with clomiphene citrate and human menopausal gonadotrophin was $£ 103$ and with buserelin $£ 361$-an increase of $£ 258$ for each cycle of treatment, mostly due to the use of increased amounts of human menopausal gonadotrophin. This is, however, more than balanced by the reduced wastage of drugs. The collection of eggs was abandoned in $20 \%$ of patients treated with clomiphene citrate who had received the full treatment with human menopausal gonadotrophin; with buserelin only $8 \%$ of patients had wasted superovulatory drugs. Moreover, the greater rate of success with buserelin, more than double that with clomiphene citrate and human menopausal gonadotrophin, meant that fewer patients returned for repeated attempts at in vitro fertilisation, a substantial financial and emotional saving in the long term. Another advantage of the use of luteinising hormone releasing hormone agonists is that as the spontaneous surge of luteinising hormone is invariably abolished the collection of eggs can be programmed for convenience. Fifty two women $(23 \%)$ in the group treated with clomiphene citrate and human menopausal gonadotrophin had a surge of luteinising hormone that necessitated arranging emergency operating time at unsocial hours, which is extremely costly, especially at weekends and at night because of the extra staffing required.

One problem with using buserelin and human menopausal gonadotrophin is the high incidence of multiple pregnancy. Once the first 50 patients in our series had been treated a considerable risk (13\%) of a triplet pregnancy was found when three or more embryos were transferred. This risk was greatest when large numbers of embryos were available for transfer, particularly in women with tubal disease as the sole cause of infertility. Consequently, later in this study we embarked on a policy of replacing only two embryos if there were more than four fertilised eggs from women with tubal disease alone. It is too early to say whether this will reduce the chance of pregnancy significantly. The incidence of loss during early pregnancy was similar in both groups of women $(17 \%$ with buserelin and $23 \%$ with clomiphene citrate) and similar to the average nationally (23\%). ${ }^{\prime}$ Unfortunately, the high incidence of multiple pregnancy resulted in increased fetal loss by abortion in the first trimester or by premature labour. This occurred to the same extent with both drug regimens and is not related to the use of buserelin. Loss of pregnancy is an extremely distressing outcome of in vitro fertilisation. A policy of reducing the number of embryos transferred to the uterus should be considered seriously by groups proposing to use this more successful method of inducing ovulation.

The risk of multiple pregnancy when large numbers of embryos are available for transfer seems to be higher after treatment with buserelin $(33 \%)$ than after conventional treatment with clomiphene 
citrate $(23 \%)$. This, together with the improvement in the rate of implantation suggests that prolonged suppression of the pituitary with buserelin may lead to improved quality of oocytes (and therefore of embryos). Further evidence for this is that only eight out of $20(40 \%)$ of women having more than four embryos available after conventional treatment conceived compared with 17 out of 20 $(85 \%)$ treated with buserelin. Alternatively, buserelin may partly produce its effect by direct action on uterine receptivity, but this factor remains to be investigated.

If the success rate reported in this study is maintained it will facilitate the use of in vitro fertilisation for preimplantation diagnosis to treat couples at risk of having a child suffering from genetic disease. An important advantage of treatment with buserelin is that large numbers of fertilisable eggs are produced during one cycle of treatment. This will allow the simultaneous screening of many zygotes for single gene defects for preimplantation diagnosis, such that women at risk could embark on a healthy pregnancy.

\section{References}

1 Voluntary Licensing Authority for Human In Vitro Fertilization and Embryology. Third report. London: Voluntary Licensing Authority, 1988. (Available from the Secretariat, 20 Park Crescent, London W'IN 4AL
2 Wood C, McMaster R, Rennie G, Trounson A, Leeton J. Factors influencing pregnancy rates following in vitro fertilization and embryo transfer. Fertil Steril 1985;43:245-50.

3 Stanger JD, Yovich JL. Reduced in-vitro fertilization of human ocytes from patients with raised basal luteinizing hormone levels during the follicular phase. Br $\mathcal{A}$ Obstet (iynaecol 1985;92: 385-93.

4 Howles CM, MacNamee MC, Edwards RG, Goswamy R, Steptoe PC. Effect of high tonic levels of luteinising hormone on outcome of in-vitro fertilization. Lancet 1986; ; $521-2$.

Salat-Baroux J, Antoine JM, Alvarez S, et al. Programmed induction of ovulation for IVFprogestins or LHRH agonists. Contraception-Fertilite-Sexualite 1987;15:761-3.

6 Lindner C, Braendle W, Lichtenberg V, Bispink L, Bettendorf G. Gonadotrophin-Stimulation und In-vitro-Fertilisation nach selektiver Hypophysen-Suppression durch I.H RH Analogon. und In-vitro-Fcrtilisation nach sclektiver

7 Franks S, Adams J, Mason H, Polson D. Ovulatory disorders in women with polycystic ovary syndrome. Clinics in Obstetrics and (ivneecology 1985;12:605-32

8 Hillier SG, Parsons jH, Margara RA, Winston RML, Crofton ME Serum oestradiol and preovulatory follicular development before in-vitro fertilization. I Endocrinol 1984:101:113-8.
pelatiol and preovulatory follicular development before in-vitro fertilization. I Endocrnol 1984;101:113-8.
McIntosh JEA, Matthews CD, Crocker JM, Broom TJ, Cox LW. Predicting the luteinising hormone surge: relationship between the duration of the follicular and luteal phases and the length of the human menstrual cycle. Feril Steril 1980;30:125-30.

10. Hillier SG, Afnan AMM, Margara RA, Winston RML. Superovulation strategy before in vitro fertilization. Clinics in Obstetrics and Gvnaecology 1985;12:687-723.

11 Fleming R, Coutts JRT. Induction of multiple follicular growth in normally menstruating women with endogenous gonadotrophin suppression. Fertil Steril 1986;45:226-30.

12 Smitz J, Devroey P, Braekmans, el al. Management of failed cycles in an IVF/GIFl programme with the combination of a GnRH analogue and HMG. Hum Reprod 1987;2:309-14.

13 MacNamee MC, Howles CM, Edwards RG. Pregnancies after IVF when high tonic L.H is reduced by long-term treatment with GnRH agonists. Hum Reprod 1987;2:569-71.

14 Fleming R Adam AH, Black WP MacNaughton MC, Couts JRT A new systematic treatment for inferile wom AH, Black WP, MacNaughton MC, Coutts JRT. A new systematic trean

Winston RML. Why a ban on embryo research would be a tragedy. Br Med f 1987;295:1501-2.

\title{
A randomised dose ranging study of recombinant tissue plasminogen activator in acute myocardial infarction
}

\author{
A J MCNEILL, J S SHANNON, S R CUNNINGHAM, D J FLANNERY, N P S CAMPBELL, \\ M M KHAN, G C PATTERSON, S W WEBB, A A J ADGEY
}

\begin{abstract}
To assess the thrombolytic efficacy and the effect on the systemic fibrinolytic system of recombinant tissue plasminogen activator doses of $20 \mathrm{mg}, 50 \mathrm{mg}$, and $100 \mathrm{mg}$ were compared in a randomised study. Tissue plasminogen activator was infused intravenously over $\mathbf{9 0}$ minutes in $\mathbf{5 0}$ consecutive patients with acute myocardial infarction of four hours' duration or less; on average the infusion was started 135 minutes (range 20 to 240) after the onset of pain. The affected artery was patent at the end of the 90 minute infusion in $14 / 17(82 \%)$ of those who received $100 \mathrm{mg}, 12 / 17(71 \%)$ of those who received $50 \mathrm{mg}$, and $8 / 16(50 \%)$ of those who received $20 \mathrm{mg}$. Regardless of dose, reperfusion rates were significantly better for patients treated within two hours of the onset of symptoms $(81 \%)$ than for those treated in the third and fourth hours $(54 \%)$. At the end of the infusion serum fibrinogen concentrations fell to $86 \%$ of the preinfusion value after $20 \mathrm{mg}, 75 \%$ after $50 \mathrm{mg}$, and $63 \%$ after $100 \mathrm{mg}$, and similar dose dependent changes occurred in plasminogen, $\alpha_{2}$ anti-
\end{abstract}

\footnotetext{
Regional Medical Cardiology Centre, Royal Victoria Hospital, Belfast BT12 6BA

A J MCNEILL, MB, MRCP, research fellow

I S SHANNON, MD, MRCP, registrar

S R CUNNINGHAM, MD, MRCP, research fellow

D J FLANNERY, MB, MRCP, research fellow

N P S CAMPBELL, MD, MRCP, consultant cardiologist

M M KHAN, $\mathrm{MB}, \mathrm{MRCP}$, consultant cardiologist

G C PATTERSON, MD, PHD, consultant cardiologist

S W WEBB, MD, MRCP, consultant cardiologist

A A J ADGEY, MD, FRCP, consultant cardiologist

Correspondence to: Dr Adgey.
}

plasmin, and fibrinogen and fibrin degradation products. The mean infarct related regional third ejection fraction was $46 \%$ for patients with grade 2 or 3 reperfusion and 35\% for those with grade 0 or 1 . Ventricular fibrillation occurred in six $(12 \%)$ patients during the infusion of tissue plasminogen activator, but no late ventricular fibrillation occurred. Bleeding was minimal, reocclusion occurred in three patients, and four patients died from cardiac causes.

Recombinant tissue plasminogen activator is an effective thrombolytic agent which produces better reperfusion rates after a 50 or $100 \mathrm{mg}$ dose than after a $20 \mathrm{mg}$ dose. The effect on the systemic fibrinolytic system is dose dependent. Successful reperfusion results in improvement of left ventricular function.

\section{Introduction}

Although streptokinase has been used as a thrombolytic agent for at least 30 years, ' its use when administered directly into a coronary artery has become feasible only with the emergence of coronary angiography as a safe procedure in acute myocardial infarction. Intravenous administration of streptokinase allows earlier, safer, and more practicable treatment than intracoronary administration.

Nevertheless, streptokinase has several potential disadvantages. It causes thrombolysis by activating plasminogen to plasmin, which in turn breaks down fibrin to fibrin degradation products. Streptokinase causes a generalised fibrinolytic state by activating plasmin in the circulation as well as at the fibrin surface of the clot. Its antigenic potential results in antibody formation with a risk of anaphylaxis and an anamnestic response on subsequent exposure, possibly during reocclusion, and the long half life makes emergency surgical intervention difficult. These disadvantages have led to the search for 